\title{
Carvacryl acetate, a derivative of carvacrol, reduces nociceptive and inflammatory response in mice
}

\author{
Samara R.B. Damasceno a , Francisco Rodrigo A.M. Oliveira ${ }^{\text {b }}$, Nathalia S. Carvalho ${ }^{\text {a }}$, Camila F.C. Brito ${ }^{\text {a }}$, \\ Irismara S. Silva ${ }^{a}$, Francisca Beatriz M. Sousa ${ }^{a}$, Renan O. Silva ${ }^{a}$, Damião P. Sousa ${ }^{c}$, André Luiz R. Barbosa ${ }^{\text {a }}$, \\ Rivelilson M. Freitas ${ }^{b}$, Jand-Venes R. Medeiros ${ }^{a}$, $*$
}

a Laboratory of Experimental Physiopharmacology, Biotechnology and Biodiversity Center Research, Federal University of Piauí, Parnaíba, Piauí, Brazil.

${ }^{\mathrm{b}}$ Department of Biochemistry and Pharmacology, Post-graduation Program in Pharmaceutics Science of Federal University of Piauí, Teresina, Piauí, Brazil

c Department of Physiology, Federal University of Paraíba, João Pessoa, Paraíba, Brazil

\section{A R T I C L E I N F O}

\section{Article history:}

Received 6 July 2013

Accepted 2 November 2013

\section{Keywords:}

Anti-inflammatory

Anti-nociceptive

Carvacryl acetate

Carvacrol

\begin{abstract}
A B S T R A C T
Aims: The present study aimed to investigate the potential anti-inflammatory and anti-nociceptive effects of carvacryl acetate, a derivative of carvacrol, in mice.

Main methods: The anti-inflammatory activity was evaluated using various phlogistic agents that induce paw edema, peritonitis model, myeloperoxidase (MPO) activity, pro and anti-inflammatory cytokine levels. Evaluation of antinociceptive activity was conducted through acetic acid-induced writhing, hot plate test, formalin test, capsaicin and glutamate tests, as well as evaluation of motor performance on rotarod test.

Key findings: Pretreatment of mice with carvacryl acetate $(75 \mathrm{mg} / \mathrm{kg})$ significantly reduced carrageenan-induced paw edema $(P<0.05)$ when compared to vehicle-treated group. Likewise, carvacryl acetate $(75 \mathrm{mg} / \mathrm{kg})$ strongly inhibited edema induced by histamine, serotonin, prostaglandin $E_{2}$ and compound $48 / 80$. In the peritonitis model, carvacryl acetate significantly decreased total and differential leukocyte counts, and reduced levels of myeloperoxidase and interleukin-1 beta (IL-1 $\beta$ ) in the peritoneal exudate. The levels of IL-10, an antiinflammatory cytokine, were enhanced by carvacryl acetate. Pretreatment with carvacryl acetate also decreased the number of acetic acid-induced writhing, increased the latency time of the animals on the hot plate and decreased paw licking time in the formalin, capsaicin and glutamate tests. The pretreatment with naloxone did not reverse the carvacryl acetate-mediated nociceptive effect.

Significance: In conclusion, the current study demonstrated that carvacryl acetate exhibited anti-inflammatory activity in mice by reducing inflammatory mediators, neutrophil migration and cytokine concentration, and antinociceptive activity due to the involvement of capsaicin and glutamate pathways.
\end{abstract}

Crown Copyright @ 2014 Published by Elsevier Inc. All rights reserved.

\section{Introduction}

Inflammation is a dynamic and complex process that arises in response towards cellular injury. It has an important role in tissue repair, yet in some cases it can cause undesirable effects such as tissue damage and loss of function. Inflammation process is characterized by the production of a cascade of mediators that regulate important factors of the inflammatory response, as the increase in vascular permeability and recruitment of leukocytes in the blood (Rodriguez-Vita and Lawrence, 2010). Once released, these inflammatory mediators may activate or sensitize nociceptors adjacent to the injured tissue resulting in pain sensation (Andrade et al., 2012). Currently several analgesics and anti-inflammatory drugs are associated with important side effects,

\footnotetext{
* Corresponding author at: Av. São Sebastião, 2819, CEP: 64202-020, Parnaíba, PI, Brazil. Tel.: + 5586 99862374; fax: + 558633235406.

E-mail address: jandvenes@ufpi.edu.br (J.-V.R. Medeiros).
}

low efficacy and specificity. For this reason, studies are conducted to identify novel therapeutic options to develop and introduce new drugs with greater safety and efficacy.

Medicinal plants are natural products known to be a significant source of new chemical substances with potential therapeutic effects (Calixto, 2005). Among natural products, use of essential oils is a promising option because of proven therapeutic action and for being also commonly added in food to obtain a specific taste (Ipek et al., 2005). In this context, we can include the carvacrol (5-isopropyl-2methylphenol), a monoterpenic phenol present in essential oils of numerous aromatic plants of the family Laminaceae (Vincenzi et al., 2004). Previous studies have demonstrated antimicrobial (Klein et al., 2013), antioxidant (Yanishlieva et al., 1999; Beena et al., 2013), antinociceptive (Melo et al., 2012) and anti-inflammatory (Landa et al., 2009) properties of this compound.

In this study, we decided to investigate a semisynthetic derivative of carvacrol, carvacryl acetate, a compound unexplored as their pharmacological properties. Since carvacrol, as well as other phenols, such as 
thymol, is more toxic than many esters, the synthesis of carvacryl acetate was performed to obtain a derivative of carvacrol with improved pharmacological profile and less toxicity. Thus we suggest that the presence of an ester group, instead of the hydroxyl group of carvacrol, may confer different safety and efficacy features to this compound compared to monortepene carvacryl.

Considering the potential use of natural products in the development of new drugs, the aim of the present study was to investigate the anti-inflammatory and antinociceptive effects of carvacryl acetate, a derivative of carvacrol, in experimental models.

\section{Materials and methods}

Drugs and reagents

$\lambda$-Carrageenan, indomethacin, serotonin, histamine, compound $48 / 80$, prostaglandin $\mathrm{E}_{2}\left(\mathrm{PGE}_{2}\right)$, acetic acid, formaldehyde and dimethyl sulfoxide (DMSO) were purchased from Sigma Chemical (Saint Louis, MO, USA). Heparin and morphine were provided by Merck, Sao Paulo, Brazil. All drugs were dissolved in sterile $0.9 \%(\mathrm{w} / \mathrm{v}) \mathrm{NaCl}$ (saline). The carvacryl acetate was dissolved in 2\% DMSO. All other chemicals were of analytical grade and obtained from standard commercial suppliers.

\section{Compounds}

Carvacryl acetate (98\% purity; Fig. 1) was obtained by acetylation of carvacrol, using acetic anhydride as acylating agent and pyridine as catalyst. As described below, first in a $50 \mathrm{ml}$ flask, equipped with magnetic stirrer, coupled to a Friedrich condenser and an inert atmosphere was added carvacrol ( $5 \mathrm{~g}, 0.033 \mathrm{~mol})$, pyridine $(7.5 \mathrm{ml})$ and acetic anhydride ( $12.5 \mathrm{ml})$. Then subjected to magnetic stirring and under constant reflux for $24 \mathrm{~h}$. Continuing the procedure for preparing the reaction mixture was poured into ice water $(60 \mathrm{ml})$ and extracted from reaction product in a separator funnel using chloroform as the solvent (three times $60 \mathrm{ml}$ ). The chloroform phases were combined and washed with saturated copper sulphate (three times $60 \mathrm{ml}$ ). The chloroform phase was washed with water (three times $60 \mathrm{ml}$ ) and dried with anhydrous $\mathrm{Na}_{2} \mathrm{SO}_{4}$. Subsequently, the solvent was evaporated on a rotary evaporator. The reaction product was subjected to column chromatography using silica gel as stationary phase and a mixture of hexane/ethyl acetate (95:5) as mobile phase. There was obtained $4.779 \mathrm{~g}(0.025 \mathrm{~mol})$ of carvacryl acetate and 76\% yield (Vogel et al., 1996; Moraes et al., 2013). The structural identification of carvacryl acetate was performed by analysis of ${ }^{1} \mathrm{H}$ and ${ }^{13} \mathrm{C}$ NMR, IR and compared with literature data.

\section{Animals}

Male Swiss mice (25-30 g) were housed at a temperature of $25 \pm 2{ }^{\circ} \mathrm{C}$ under a 12/12-h light/dark cycle with food and water ad libitum. All experiments were performed in accordance with the Guide for Care and Use of Laboratory Animals (National Institute of Health, Bethesda, MD, USA) and were approved by the Ethics Committee in Research of the Federal University of Piauí (protocol no. 0066/10).

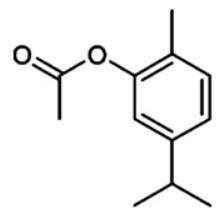

Fig. 1. Chemical structure of carvacryl acetate.
Experimental protocol

\section{Carrageenan-induced paw edema in mice}

The animals were randomly divided into six groups $(n=5)$, and edema was induced by injection of $50 \mu \mathrm{l}$ of a suspension of carrageenan $(500 \mu \mathrm{g} / \mathrm{paw})$ in $0.9 \%$ sterile saline into the right hind paw (group I) according Silva et al. (2013). Mice were pretreated intraperitoneally (i.p.) with either 2\% DMSO (group II untreated control); indomethacin $10 \mathrm{mg} / \mathrm{kg}$ (group III reference control); or carvacryl acetate, 25,50 or $75 \mathrm{mg} / \mathrm{kg}$ (groups IV, V, and VI, respectively). Paw volume was measured immediately before $\left(V_{0}\right)$, and at $1,2,3$, and $4 \mathrm{~h}$ after carrageenan treatment (Vt), using a plethysmometer (Panlab, Barcelona, Spain). The effect of pretreatment was calculated as percent inhibition of edema relative to the paw volume of the DMSO-treated controls by using the following formula (Winter et al., 1962).

\% inhibition of edema $=\frac{\left(\mathrm{V}_{\mathrm{t}}-\mathrm{V}_{0}\right) \text { Control }-\left(\mathrm{V}_{\mathrm{t}}-\mathrm{V}_{0}\right) \text { Treated }}{\left(\mathrm{V}_{\mathrm{t}}-\mathrm{V}_{0}\right) \text { Control }} \times 100$

\section{Paw edema induced by different phlogistic agents}

To induce edema, the animals were administered $50 \mu$ injections of serotonin $(1 \% \mathrm{w} / \mathrm{v})$, histamine $(100 \mu \mathrm{g} / \mathrm{paw})$, prostaglandin $\mathrm{E}_{2}$ ( $3 \mathrm{nmol} / \mathrm{paw}$ ), or compound $48 / 80(12 \mu \mathrm{g} / \mathrm{paw}$ ) into the right hind paw (Silva et al., 2013; Chaves et al., 2013; Claudino et al., 2006). The contralateral paw received $50 \mu \mathrm{l}$ of $2 \%$ DMSO and served as an untreated control. In the experiment, the animals were pretreated with carvacryl acetate $(75 \mathrm{mg} / \mathrm{kg}$, i.p.) or indomethacin $(10 \mathrm{mg} / \mathrm{kg}$, i.p.; reference control) $30 \mathrm{~min}$ before these intraplantar injections of phlogistic agents.

\section{Carrageenan-induced peritonitis}

For the determination of neutrophil migration into the peritoneal cavity, mice were injected intraperitoneally with 2.0\% DMSO, indomethacin $10 \mathrm{mg} / \mathrm{kg}$ or carvacryl acetate ( $75 \mathrm{mg} / \mathrm{kg}$, i.p.). Thirty minutes later, the animals were injected with carrageenan $(250 \mu \mathrm{l} ; 500 \mu \mathrm{g} / \mathrm{cavi}$ ty), as adapted from de reports of Chaves et al. (2013). Mice were euthanized $4 \mathrm{~h}$ later and the peritoneal cavity was washed with $1.5 \mathrm{ml}$ of heparinized phosphate buffered saline (PBS) to harvest peritoneal cells. The volumes recovered were similar in all experimental groups and were equivalent to $~ 95 \%$ of the injected volume. Total cell counts were performed in a Neubauer chamber, and differential cell counts (100 cells total) were carried out on cytocentrifuge slides stained with hematoxylin and eosin. The results are presented as the number of neutrophils per milliliter of peritoneal exudate. Aliquots of the peritoneal exudates were stored at $-70{ }^{\circ} \mathrm{C}$ for later analysis of cytokine and myeloperoxidase (MPO) content.

\section{Myeloperoxidase activity assay}

MPO assay was based on the method of Bradley et al. (1982) and partly modified. Briefly, $400 \mu \mathrm{l}$ of the peritoneal exudates was centrifuged at $40,000 \times \mathrm{g}$ for $7 \mathrm{~min}$ at $4{ }^{\circ} \mathrm{C}$. After, $10 \mu \mathrm{l}$ of the supernatants were collected and MPO activity was assayed by measuring the change in absorbance at $450 \mathrm{~nm}$ using 0 -dianisidin edihydrochloride and 1\% hydrogen peroxide. The results were expressed in units $/ \mathrm{ml}$. A unit of MPO activity was defined as that converting $1 \mu \mathrm{mol}$ of hydrogen peroxide to water in $1 \mathrm{~min}$ at $22^{\circ} \mathrm{C}$.

Evaluation of TNF- $\alpha, I L-1 \beta$ and IL-10 levels in carrageenaninduced peritonitis

Levels of tumor necrosis factor-alpha (TNF- $\alpha$ ), interleukin- 1 beta (IL-1 $\beta$ ) and interleukin-10 (IL-10) were evaluated using sandwich ELISA. Briefly, microliter plates were coated overnight at $4{ }^{\circ} \mathrm{C}$ with antibody against mice TNF- $\alpha$, IL-1 $\beta$ or IL-10 ( $2 \mu \mathrm{g} / \mathrm{ml}$, DuoSet ELISA Development kit R\&D Systems). Blocking of nonspecific binding sites was accomplished by incubating plates with PBS containing $2 \%$ bovine serum albumin (BSA) for $90 \mathrm{~min}$ at $37^{\circ} \mathrm{C}$. After blocking the plates, 
the test samples and each standard at various dilutions were added in duplicate and incubated at $4{ }^{\circ} \mathrm{C}$ for $24 \mathrm{~h}$. The plates were washed three times with buffer. After washing the plates, $50 \mu$ of biotinylated sheep polyclonal anti-TNF- $\alpha$, anti-IL-1 $\beta$ or IL-10 (diluted 1:1000 with assay buffer $1 \%$ BSA) were added to the wells. After further incubation at room temperature for $1 \mathrm{~h}$, the plates were washed and $50 \mu \mathrm{l}$ of streptavidin-HRP diluted 1:5000 were added to all wells. The reagent o-phenylenediamine dihydrocloride $(50 \mu \mathrm{l})$ was added 15 min later, and the plates were incubated in the dark at $37{ }^{\circ} \mathrm{C}$ for $15-20 \mathrm{~min}$. After color development, the reaction was stopped with the addition of sulfuric acid (1 M) and absorbance was measured at $490 \mathrm{~nm}$. The results are expressed as $\mathrm{pg} / \mathrm{mg}$ protein and reported as mean \pm SEM.

\section{Acetic acid-induced abdominal writhing}

Acetic acid administration causes irritation, resulting in painful contortions, followed by hind limb extension. Each experimental group was pretreated with DMSO, carvacryl acetate ( $75 \mathrm{mg} / \mathrm{kg}$, i.p.) or morphine ( $5 \mathrm{mg} / \mathrm{kg}$, s.c., reference control). After $30 \mathrm{~min}, 0.6 \%$ acetic acid (10 ml/kg body weight, i.p.) was administered. After waiting for $10 \mathrm{~min}$, the number of constrictions, including abdominal muscle contractions and hind paw extension, were recorded over $20 \mathrm{~min}$, as described by Koster et al. (1959).

\section{Hot plate test}

Mice were treated according to the method described by Eddy and Leimbach (1953). Each mouse was dropped twice on a heated plate $\left(55 \pm 1{ }^{\circ} \mathrm{C}\right.$ ), separated by a $30 \mathrm{~min}$ interval. The first trial familiarized the animal with the test procedure and the second served as the control reaction time (licking of a paw or jumping), recorded as the response latency on a hot plate (Insight, Ribeirao Preto, São Paulo, Brazil; model EFF-361). Animals with baseline latencies of more than $20 \mathrm{~s}$ were excluded from the study. Mice were treated with carvacryl acetate ( $75 \mathrm{mg} / \mathrm{kg}$, i.p.) or morphine ( $5 \mathrm{mg} / \mathrm{kg}$, s.c.; reference drug) $30 \mathrm{~min}$ before the test, and the control group received the same volume of $2 \%$ DMSO. Measurements were performed before (zero time) and 30, 60 and 90 min after treatment, with a cutoff time of $45 \mathrm{~s}$ to prevent development of paw lesion.

\section{Formalin-induced licking}

Mice were pretreated with either 2\% DMSO, carvacryl acetate, ( $75 \mathrm{mg} / \mathrm{kg}$, i.p.), or morphine $(5 \mathrm{mg} / \mathrm{kg}$, s.c.; reference control). Thirty minutes after administration, $2.8 \%$ formalin $(20 \mu \mathrm{l})$ was administered subcutaneously (s.c.) into the right hind paw. Licking time was recorded from 0 to $5 \mathrm{~min}$ (phase 1, corresponding to a direct chemical stimulation of nociceptors) and 20-25 min after formalin injection (phase 2, involving release of inflammatory mediators) (Fasmer et al., 1986).

\section{Evaluation of the opioid pathway}

To examine the involvement of opioid receptors in the antinociceptive activity of carvacryl acetate for formalin-induced pain, mice $(n=6)$ were pretreated with $2 \%$ DMSO or naloxone $(3 \mathrm{mg} / \mathrm{kg}$, sc; opioid antagonist). After $15 \mathrm{~min}$, the animals were treated with carvacryl acetate ( $75 \mathrm{mg} / \mathrm{kg}$, i.p.) or morphine $(5 \mathrm{mg} / \mathrm{kg}$, s.c.; opioid agonist). Thirty minutes after administration, $2.8 \%$ formalin (20 $\mu \mathrm{l})$ was administered subcutaneously (s.c.) into the right hind paw. Licking time was recorded from 0 to $5 \mathrm{~min}$ (phase 1, corresponding to a direct chemical stimulation of nociceptors) (Hunskaar et al., 1985).

\section{Capsaicin-induced nociception}

The animals were treated with vehicle ( $2 \%$ DMSO, i.p.), carvacryl acetate (75 mg/kg, i.p.) or morphine ( $5 \mathrm{mg} / \mathrm{kg}$, s.c.; reference control), thirty minutes later mice received $20 \mu \mathrm{l}$ of capsaicin solution ( $3 \mu \mathrm{g} / \mathrm{paw})$ in the right hind paw. The nociceptive response (time that the animal remained licking or biting the injected paw) was timed over a period of 5 min after capsaicin administration (Sakurada et al., 2003).

\section{Glutamate-induced nociception}

The animals were treated with carvacryl acetate $(75 \mathrm{mg} / \mathrm{kg}$, i.p.) or MK-801 (0.03 mg/kg, i.p.; an NMDA receptor antagonist), thirty minutes later mice received $20 \mu \mathrm{l}$ of glutamate solution ( $30 \mu \mathrm{mol} / \mathrm{paw}$ ) in the right hind paw. The nociceptive response (time that the animal remained licking or biting the injected paw) was timed over a period of 15 min after glutamate administration (Beirith et al., 2002).

\section{Evaluation of the motor performance}

The rota-rod test permits the detection of muscle relaxing agents or drugs that produce motor incoordination. Earlier, the animals were evaluated to select those that shown ability in walking on the revolving bar under the same conditions used in the test and these were divided into groups $(n=5)$. On the day of the test, animals were treated with $0.5 \mathrm{ml} / 25 \mathrm{~g}$ vehicle (2\% DMSO-control, i.p.), carvacryl acetate ( $75 \mathrm{mg} / \mathrm{kg}$, i.p.) or diazepam ( $5 \mathrm{mg} / \mathrm{kg}$, v.o., positive control for motor impairment). After $60 \mathrm{~min}$, the animals were placed on the horizontal rotating bar (12 rpm), which was a non-slip plastic rod located $28 \mathrm{~cm}$ over the base, for $1 \mathrm{~min}$. The number of falls was counted, with a maximum of three replacements on the bar (Dunham and Miya, 1957).

\section{Statistical analysis}

Results are expressed as means \pm SEM of at least five animals per group, and statistical analysis was performed using one-way analysis of variance (ANOVA) followed by the Newman-Keuls post hoc test, when appropriate. Statistical significance was set at $P<0.05$.

\section{Results}

\section{Carrageenan-induced paw edema}

Subplantar injection of carrageenan promoted an increase in paw volume dependent on the time; this increase was maintained until the fourth hour, getting the maximum value at the third hour (Table 1). Paw edema was significantly decreased by indomethacin $(P<0.05)$ throughout the experimental period, with a maximal inhibition of $81.3 \%$, at the third hour. The carvacryl acetate were evaluated at the doses of 25,50 and $75 \mathrm{mg} / \mathrm{kg}$, where was observed significant inhibition of edema at a dose of $75 \mathrm{mg} / \mathrm{kg}$ at all times evaluated, granting the maximum of inhibition at the third and fourth hour, $88.8 \%(P<0.001)$ and 97\% $(P<0.001)$ respectively, when compared to the carrageenan group. Because the dose of $75 \mathrm{mg} / \mathrm{kg}$ afforded most of the protection against the inflammatory effects caused by carrageenan, this dose was selected for the study of the carvacryl acetate-mediated antiinflammatory and anti-nociceptive effects.

\section{Paw edema induced by different phlogistic agents}

Carvacryl acetate (75 mg/kg, i.p.) significantly decreased the paw edema elicited by histamine, prostaglandin $\mathrm{E}_{2}$, compound $48 / 80$ and serotonin (Fig. 2). The paw edema was most pronounced in the first thirty minutes after the subplantar injection of phlogistic agents. The peak inhibitory effects observed at the time of half hour with the dose of $75 \mathrm{mg} / \mathrm{kg}$ of carvacryl acetate in the edemas of histamine (Fig. 2a), prostaglandin $\mathrm{E}_{2}\left(\mathrm{PGE}_{2}\right.$ (Fig. 2b), compound 48/80 (Fig. 2c) and serotonin (Fig. 2d) were 34.14\% $(P<0.001), 96.48 \%(P<0.001), 83.33 \%$ $(P<0.001)$ and $37.50 \%(P<0.01)$, respectively. The reference drug, indomethacin $(10 \mathrm{mg} / \mathrm{kg}$, i.p.), inhibited paw edema induced by all these inflammatory mediators significantly.

\section{Carrageenan-induced peritonitis}

Peritoneal inflammation was induced and the number of cells recruited into the peritoneal cavity was measured as an indication of the inflammation degree. After the induction of inflammation by carrageenan, the total leukocyte count in the peritoneal cavity in carrageenan 
Table 1

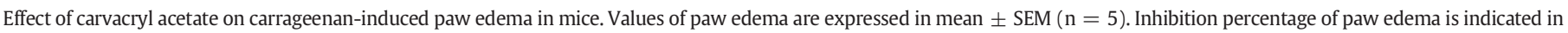
parenthesis.

\begin{tabular}{|c|c|c|c|c|c|}
\hline \multirow[t]{2}{*}{ Treatment } & \multirow[t]{2}{*}{ Dose $(\mathrm{mg} / \mathrm{kg})$} & \multicolumn{4}{|l|}{ Paw edema (ml) } \\
\hline & & $1 \mathrm{~h}$ & $2 \mathrm{~h}$ & $3 \mathrm{~h}$ & $4 \mathrm{~h}$ \\
\hline DMSO & & $0.002 \pm 0.002$ & $0.002 \pm 0.002$ & $0.002 \pm 0.002$ & $0.002 \pm 0.002$ \\
\hline Control (Cg) & & $0.058 \pm 0.019$ & $0.060 \pm 0.014$ & $0.107 \pm 0.016$ & $0.066 \pm 0.006$ \\
\hline Indomethacin & 10 & $0.012 \pm 0.007 *(79.3)$ & $0.014 \pm 0.011^{*}(76.7)$ & $0.020 \pm 0.015^{* *}(81.3)$ & $0.014 \pm 0.011^{* * *}(78.8)$ \\
\hline \multirow[t]{3}{*}{ Carvacryl Acetate } & 25 & $0.054 \pm 0.006(06.9)$ & $0.040 \pm 0.012(33.3)$ & $0.054 \pm 0.012^{*}(49.5)$ & $0.060 \pm 0.012(09.09)$ \\
\hline & 50 & $0.040 \pm 0.013(31.0)$ & $0.048 \pm 0.012(20.0)$ & $0.046 \pm 0.006^{*}(57.0)$ & $0.050 \pm 0.011(24.24)$ \\
\hline & 75 & $0.016 \pm 0.005^{*}(72.4)$ & $0.014 \pm 0.006^{*}(76.7)$ & $0.012 \pm 0.005^{\text {*** }}(88.8)$ & $0.002 \pm 0.002^{* * *}(97.0)$ \\
\hline
\end{tabular}

$* \mathrm{p}<0.05$ compared with control.

** $\mathrm{p}<0.01$ compared with control.

*** $\mathrm{p}<0.001$ compared with control (one way ANOVA followed by Newman-Keuls' test).

group was $13220 \times 10^{3} \pm 2610 \times 10^{3}$ cells $/ \mathrm{ml}$. The pre-treatment with the carvacryl acetate $(75 \mathrm{mg} / \mathrm{kg})$ decreased the number of leukocytes total count to $2720 \times 10^{3} \pm 681.3 \times 10^{3}$ cells $/ \mathrm{ml}$ (79.42\% inhibition, $P<0.001)$ (Fig. 3a). The carvacryl acetate $\left(1805 \times 10^{3} \pm 400.7 \times\right.$ $10^{3}$ cells $/ \mathrm{ml} ; 84.18 \%$ inhibition, $P<0.001$ ) also significantly decreased the neutrophil migration into the peritoneal cavity, as compared to carrageenan group $\left(11410 \times 10^{3} \pm 2392 \times 10^{3}\right.$ cells/ml) (Fig. 3b). Similarly, when compared to carrageenan treatment, pretreatment with indomethacin produced an $82.2 \%$ reduction $(P<0.001)$ in total leukocyte count and a $94.3 \%$ reduction $(P<0.001)$ in neutrophil migration to the peritoneal cavity.

\section{Myeloperoxidase activity assay}

Table 2 shows that carvacryl acetate $(75 \mathrm{mg} / \mathrm{kg}$ ) inhibited neutrophil infiltration, which was evident from the myeloperoxidase (MPO) activity measured in the peritoneal exudate. Pretreatment of mice with carvacryl acetate reduced MPO activity to $4.1 \pm 0.6 \mathrm{U} / \mathrm{ml}$ versus
$7.6 \pm 0.8 \mathrm{U} / \mathrm{ml}$ of the carrageenan group, which was equivalent to a reduction of $46.05 \%(P<0.05)$.

Evaluation of TNF- $\alpha, I L-1 \beta$ and IL-10 levels in carrageenaninduced peritonitis

The intraperitoneal administration of carrageenan caused a large increase in levels of TNF- $\alpha$ and IL1- $\beta$ (202.20 $\pm 19.97 \mathrm{pg} / \mathrm{ml}$ and $1995 \pm 13.19 \mathrm{pg} / \mathrm{ml}$, respectively) in peritoneal exudate, when compared to untreated animals ( $36.67 \pm 12.57 \mathrm{pg} / \mathrm{ml}$ in levels of TNF- $\alpha$ and $53.78 \pm 32.93 \mathrm{pg} / \mathrm{ml}$ in levels of IL1- $\beta$ ). Pretreatment of animals with carvacryl acetate $(75 \mathrm{mg} / \mathrm{kg}$; i.p.) significantly reduced the concentrations of IL1- $\beta$ to $951.1 \pm 143.3 \mathrm{pg} / \mathrm{ml}$ (52.32\% inhibition, $P<0.001$ ), when compared to carrageenan group, but did not decrease TNF- $\alpha$ levels (Table 2). On the other hand, pretreatment with carvacryl acetate $(75 \mathrm{mg} / \mathrm{kg}$; i.p.) induced a significant increase of IL-10 levels $(71.46 \pm 11.69 \mathrm{pg} / \mathrm{ml})$ in peritoneal exudate when compared to control group (Cg: $28.03 \pm 08.18 \mathrm{pg} / \mathrm{ml})$.
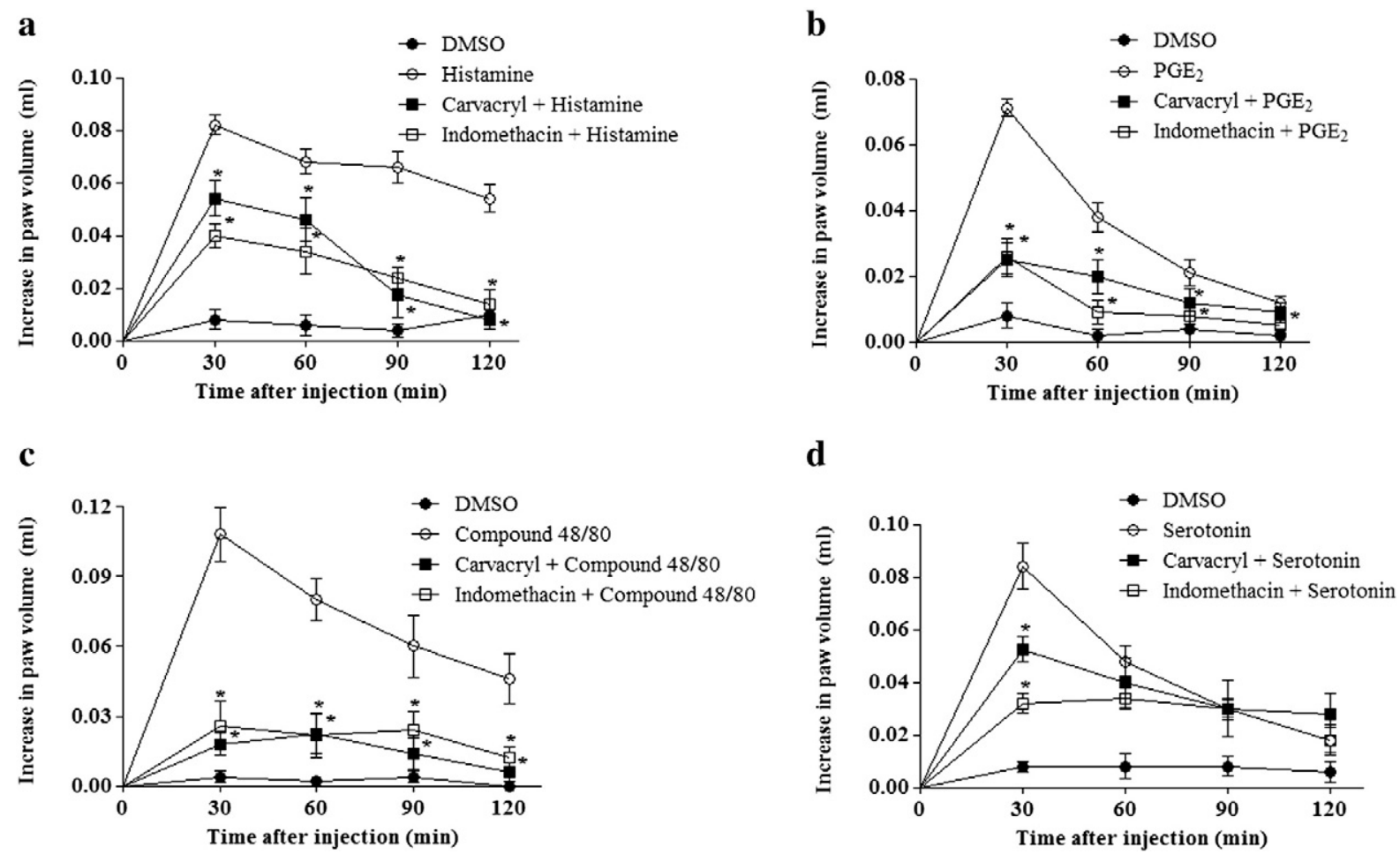

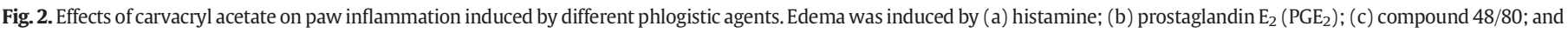

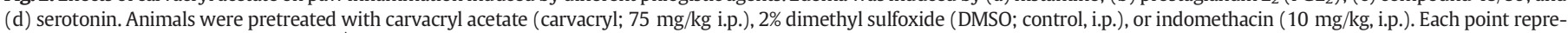
sents the mean \pm SEM of five animals. ${ }^{*} P<0.05$ significantly different from the control group. 

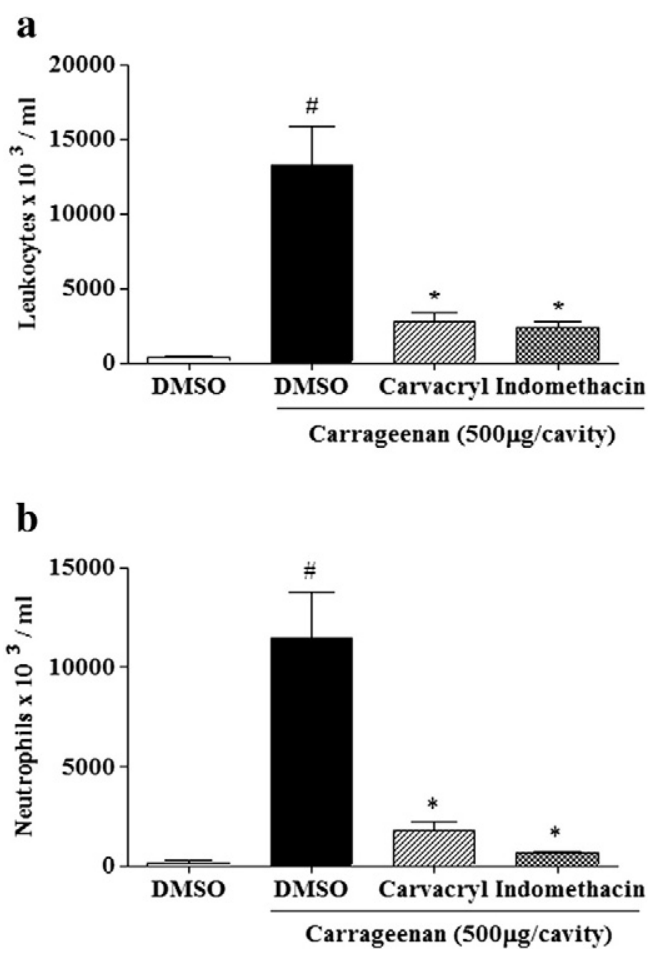

Fig. 3. Anti-inflammatory effect of carvacryl acetate on carrageenan-induced peritonitis in mice. Mice were injected i.p. with dimethyl sulfoxide (DMSO), carvacryl acetate (carvacryl; $75 \mathrm{mg} / \mathrm{kg}$ ), or indomethacin $(10 \mathrm{mg} / \mathrm{kg}$, reference control) and were injected with $250 \mu \mathrm{l}$ of carrageenan ( $500 \mu \mathrm{g} / \mathrm{cavity}$, i.p.) $30 \mathrm{~min}$ later. Neutrophil migration was evaluated after $4 \mathrm{~h}$. The white bars represent the peritoneal neutrophils in animals injected with DMSO (untreated group). (a) Total counts and (b) differential counts. The values are means \pm SEM of five animals for each group $\left({ }^{\#} P<0.05\right.$ compared to the DMSO group; ${ }^{*} P<0.05$ compared to the carrageenan group).

\section{Acetic acid-induced abdominal writhing}

Fig. 4 shows that the number of abdominal writhing in mice, induced by acetic acid, in the period of 20 min was $26.75 \pm 8.18$. The pretreatment with the carvacryl acetate $(75 \mathrm{mg} / \mathrm{kg}$, i.p.) decreased the number of writhing to $10.33 \pm 4.24$, granting an inhibition of $61.39 \%$ $(P<0.05)$. The morphine $(5 \mathrm{mg} / \mathrm{kg}$, s.c.), an opioid receptor agonist, reduced in $94.77 \%(P<0.05)$ the number of writhing, when compared with the acetic acid group, as expected.

\section{Hot plate test}

Pretreatment with the carvacryl acetate ( $75 \mathrm{mg} / \mathrm{kg}$, i.p.) significantly increased latency time on the plate in all the evaluated times $(30,60$ and $90 \mathrm{~min}$ ), as compared to time zero. Likely, treatment with morphine $(5 \mathrm{mg} / \mathrm{kg}$, s.c.) induced a significant increase in latency time in the hot plate test, throughout the experimental period (Fig. 5).

\section{Formalin-induced licking}

As shown in Fig. 6a, the 2.8\% formalin administration caused an elevated licking time in the paw in the first and in the second phase

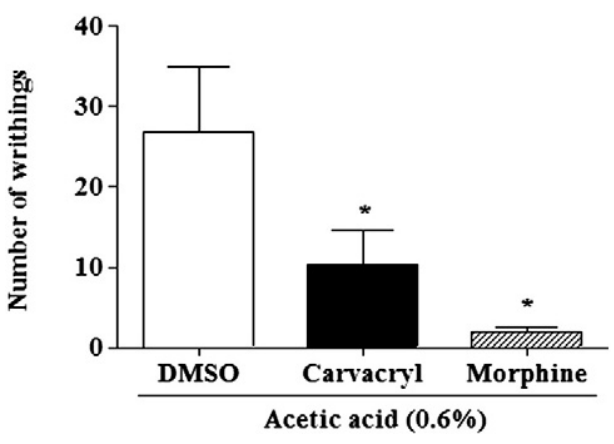

Fig. 4. Effect of carvacryl acetate on the writhing response induced by acetic acid in mice Mice received dimethyl sulfoxide (DMSO), carvacryl acetate (carvacryl; $75 \mathrm{mg} / \mathrm{kg}$, i.p.), or morphine ( $5 \mathrm{mg} / \mathrm{kg}$, s.c.; reference control), $30 \mathrm{~min}$ prior to $0.6 \%$ acetic acid ( $250 \mu \mathrm{l} /$ cavity; i.p.). Data are expressed as the means \pm SEM of five animals for each group $\left({ }^{*} P<0.05\right.$ indicates a significant difference from the acetic acid group).

$(60.36 \pm 12.91$ and $37.28 \pm 11.19$ s, respectively; Fig. $6 a)$. The pretreatment with carvacryl acetate $(75 \mathrm{mg} / \mathrm{kg}$, i.p.) reverted significantly the licking time in both the neurogenic $(63.99 \%, P<0.05)$ and inflammatory $(93.30 \%, P<0.01)$ phases. Similarly, the morphine administration also reverted the pain induced by formalin, decreasing the licking times in 57.38\% $(P<0.05)$ in the phase 1 and 98.23\% $(p<0.05)$ in the phase 2 . The Fig. $6 \mathrm{~b}$ shows that the pretreatment of animals with naloxone ( $3 \mathrm{mg} / \mathrm{kg}$, s.c.), a nonselective opioid antagonist, did not change the carvacryl acetate-mediated antinociceptive effect, however largely reversed the anti-nociceptive effect caused by morphine when analyzed in the early phase of the formalin test $(3.88 \pm 1.49 \mathrm{~s}$ in morphine group versus $26.57 \pm 4.75 \mathrm{~s}$ in naloxone group).

\section{Capsaicin-induced nociception}

Fig. 7 illustrates that the capsaicin ( $3 \mu \mathrm{g} / \mathrm{paw}$ ) administration caused accentuated hypernociception in mice, with a licking time of the paw of $33.08 \pm 1.27 \mathrm{~s}$. In addition, the carvacryl acetate $(75 \mathrm{mg} / \mathrm{kg}$, i.p.) administration $30 \mathrm{~min}$ before of capsaicin promoted accentuated decrease in licking response, with an inhibition percentage of $53.27 \%(P<0.001)$. As expected, the morphine also reverted significantly the hypernociception $(87.34 \%, P<0.001)$.

\section{Glutamate-induced nociception}

In the glutamate-induced hyperalgesia (Fig. 8), the carvacryl acetate ( $75 \mathrm{mg} / \mathrm{kg}$, i.p.) caused pronounced anti-nociception, with $55.92 \%$ inhibition $(P<0.05)$ in licking response $(56.05 \pm 11.21 \mathrm{~s}$ in glutamate group versus $24.71 \pm 9.45 \mathrm{~s}$ in carvacryl acetate-treated group). The MK-801, a non-competitive antagonist of glutamate receptor, also inhibited in a significant way the hyperalgesia caused by glutamate (65.96\% reduction, $P<0.05$ ).

\section{Evaluation of the motor performance}

The carvacryl acetate $(75 \mathrm{mg} / \mathrm{kg})$ did not affect the number of falls or time of stay on the rotating bar, when compared with the vehicle in rotarod test. As opposed, diazepam administration, positive control for

Table 2

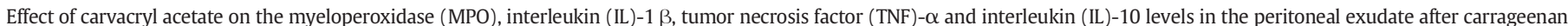
injection.

\begin{tabular}{|c|c|c|c|c|c|}
\hline Treatment & Dose (mg/kg) & $\mathrm{MPO}(\mathrm{U} / \mathrm{ml})$ & $\mathrm{IL}-1 \beta(\mathrm{pg} / \mathrm{ml})$ & TNF- $\alpha(\mathrm{pg} / \mathrm{ml})$ & $\mathrm{IL}-10(\mathrm{pg} / \mathrm{ml})$ \\
\hline DMSO & & $2.14 \pm 0.24$ & $53.78 \pm 32.93$ & $36.67 \pm 12.57$ & $16.32 \pm 04.28$ \\
\hline Control (Cg) & & $7.69 \pm 0.80$ & $1995.0 \pm 13.19$ & $202.20 \pm 19.97$ & $28.03 \pm 08.18$ \\
\hline Indomethacin & 10 & $4.37 \pm 1.45^{*}(43.1)$ & $1192.0 \pm 175.20^{* * *}(40.2)$ & $80.77 \pm 27.32^{*}(60.0)$ & $65.21 \pm 09.26^{*}$ \\
\hline Carvacryl Acetate & 75 & $4.10 \pm 0.66^{*}(46.6)$ & $951.10 \pm 143.30^{* * *}(52.3)$ & $119.10 \pm 51.86(41.0)$ & $71.46 \pm 11.69^{*}$ \\
\hline
\end{tabular}

Results are expressed as the mean \pm SEM of five animals per group $\left({ }^{*} p<0.05\right.$ compared to the carrageenan group. ${ }^{* * *} p<0.001$ compared to the carrageenan group). 


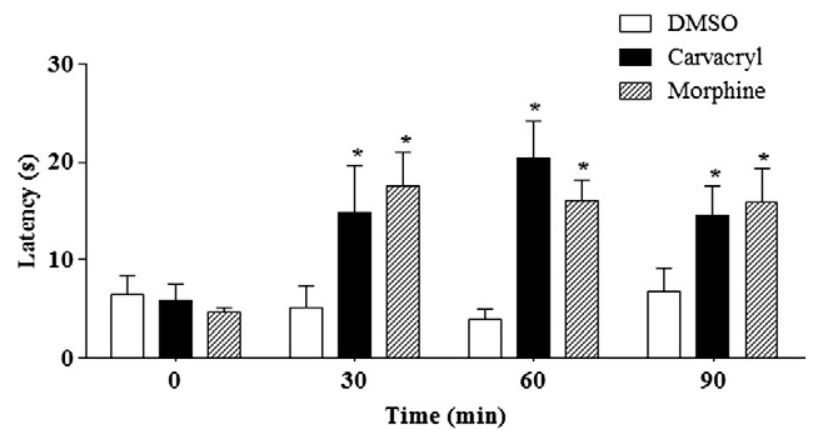

Fig. 5. Effect of carvacryl acetate on reaction times to thermal stimuli (hot plate). Mice received dimethyl sulfoxide (DMSO), carvacryl acetate (carvacryl; $75 \mathrm{mg} / \mathrm{kg}$, i.p.), or morphine ( $5 \mathrm{mg} / \mathrm{kg}$, s.c.). Data are expressed as the means \pm SEM of five animals for each group $\left({ }^{*} P<0.05\right.$ when compared with the time zero).

motor impairment, changed significantly the motor performance of the tested animals, increasing the number of falls and decreasing time of stay on the rotating bar.

\section{Discussion}

In the present study, we evaluated the potential anti-inflammatory and anti-nociceptive effects of carvacryl acetate, a derivative of carvacrol, through the use of several pharmacological tools. Our results showed that the carvacryl acetate presents significant anti-inflammatory and anti-nociceptive effects.

Inflammation is a biological reaction to an injured tissue homeostasis (Medzhitov, 2008), which involves redness, edema, rise in temperature, pain and loss of function (Bano et al., 2013). Among these

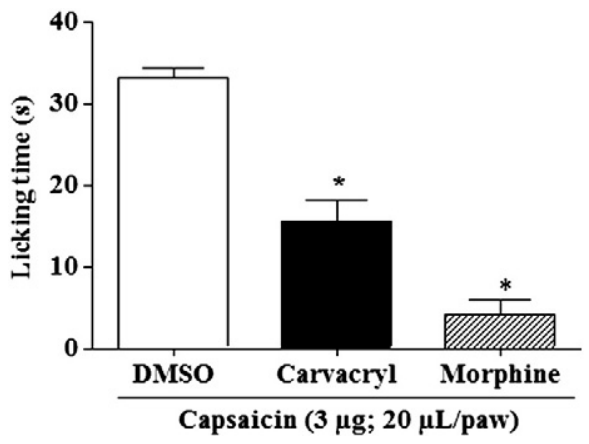

Fig. 7. Evaluation of the opioid pathway on the analgesic effect of carvacryl acetate. Mice were pretreated with $2 \%$ DMSO or naloxone ( $3 \mathrm{mg} / \mathrm{kg}$, s.c., opioid antagonist). After $30 \mathrm{~min}$, the animals were treated with carvacryl acetate (carvacryl; $75 \mathrm{mg} / \mathrm{kg}$, i.p.) or morphine ( $5 \mathrm{mg} / \mathrm{kg}$, s.c.). After $60 \mathrm{~min}$, the time spent licking was determined during the first $0-5$ min (phase 1 ) after injection with $2.8 \%$ formalin. Data are expressed as the means \pm SEM of six animals for each group $\left({ }^{*} P<0.05\right.$ indicates significant difference from the formalin group; ${ }^{\#} P<0.05$ indicates significant difference from the respective group).

parameters triggered by inflammation, edema and pain formation are targets for studies in the search for new compounds with antiinflammatory and analgesic activities.

Carrageenan-induced paw edema is widely used for determining the biphasic event of inflammation that involves the participation of diverse set of inflammatory mediators and intense neutrophil infiltration (Morris et al., 2003). The first phase of this experimental model has been attributed to the action of mediators such histamine, serotonin and bradykinin on vascular permeability (Niazi et al., 2009). The second phase is characterized by an excess production of prostaglandins and an intense neutrophil infiltrate (Perez-Gurrero et al., 2001; Déciga-Campos a

First phase

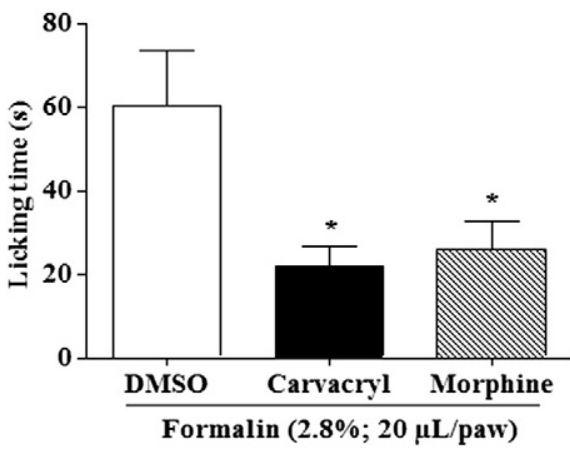

Second phase

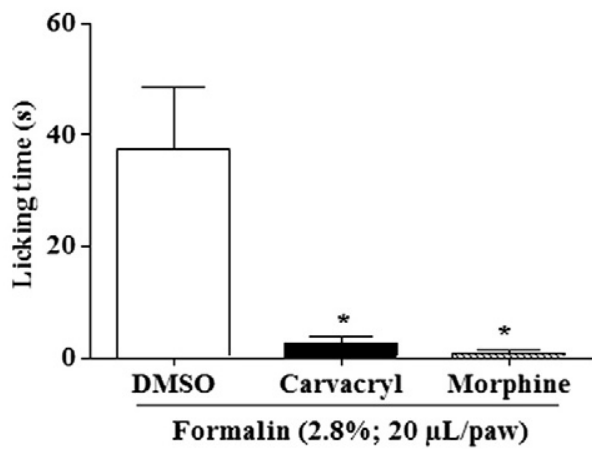

b

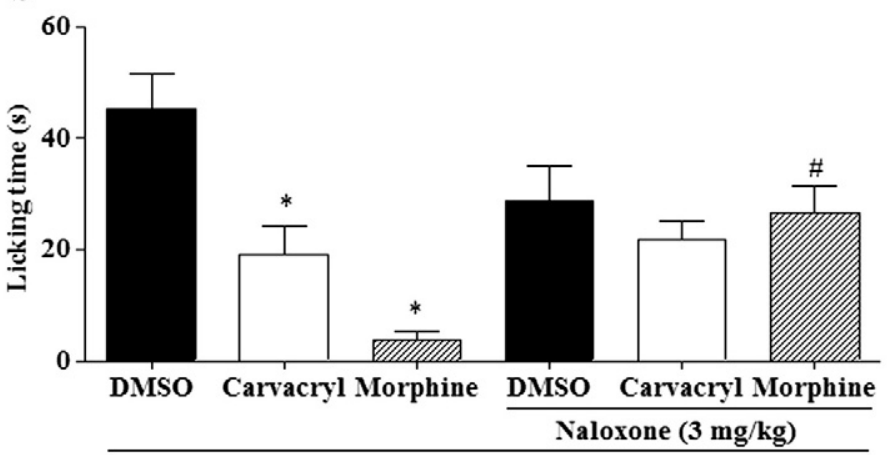

Formalin $(2.8 \% ; 20 \mu \mathrm{L} /$ paw $)$

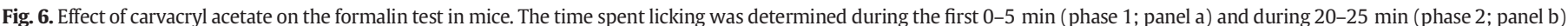

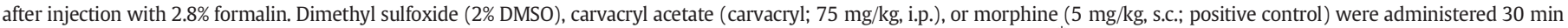

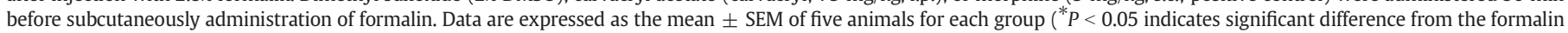
group). 


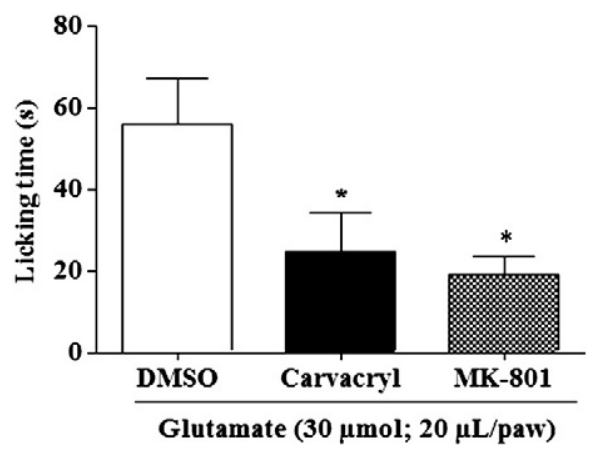

Fig. 8. Effect of carvacryl acetate on the capsaicin-induced nociception in mice. The time spent licking was determined during the first 0-5 min after injection with capsaicin solution (3 $\mu \mathrm{g} / \mathrm{paw}$ ). Dimethyl sulfoxide (DMSO, control), carvacryl acetate (carvacryl; $75 \mathrm{mg} / \mathrm{kg}$, i.p.), or morphine ( $5 \mathrm{mg} / \mathrm{kg}$, s.c.; positive control) were administered $30 \mathrm{~min}$ before intradermal administration of capsaicin. Data are expressed as the mean \pm SEM of five animals for each group ( ${ }^{*} \mathrm{P}<0.05$ indicates significant difference from the capsaicin group).

et al., 2007). In the present work, we evaluated the inhibitory potential of the carvacryl acetate on the carrageenan edema, where we observed that the carvacryl acetate caused significant reduction of edema at all times evaluated, suggesting that its anti-edematogenic effect is probably due to the inhibition of different aspects and chemical mediators of inflammation.

To confirm the involvement of these mediators in the antiinflammatory effect provided by carvacryl acetate we realize the paw edema induced by compound $48 / 80$, histamine, serotonin and prostaglandin $\mathrm{E}_{2}$. Compound $48 / 80$ causes massive mast cell degranulation that promotes the release of inflammatory mediators such as histamine, serotonin, platelet-activating factor, leukotrienes and a variety of cytokines that can elicit many events associated with inflammation (Datti et al., 2002; Coussens and Werb, 2002). Among these agents, histamine and serotonin are important inflammation mediators; they are potent vasodilator substances and also increase the vascular permeability (Linardi et al., 2000). The carvacryl acetate significantly reversed the edema induced by compound $48 / 80$, histamine and serotonin. Thus, it is possible to confirm the involvement of vasoactive mediators derived from mast cell granules, such as histamine and serotonin, in the carvacryl acetate anti-inflammatory effect.

$\mathrm{PGE}_{2}$ is synthesized in substantial amounts at the sites of inflammation, and it acts as a potent vasodilator, inducing the production of various chemo-attractants, such as leucocytes and pro-inflammatory cytokines including IL-1 $\beta$ and TNF- $\alpha$ (Kaur et al., 2004). This mediator also participates in acute pain, sensitising the nerve endings of nociceptive fibres $A \delta$ and C through its receptor EP1 (Rady et al., 2001). Thus, high levels of $\mathrm{PGE}_{2}$ have been found in inflammatory exudates, and the injection of $\mathrm{PGE}_{2}$ directly into tissue has been shown to induce a number of classical sign of inflammation (Claudino et al., 2006). The carvacryl acetate also significantly reduced the edema induced by $\mathrm{PGE}_{2}$, demonstrating that the carvacryl acetate-mediated anti-inflammatory effect also involves the decrease of this important inflammatory mediator.

Leukocyte migration to injured tissue is another important aspect of the inflammatory process (González et al., 2013). To evaluate the participation of leukocyte migration in the anti-inflammatory activity mediated by carvacryl acetate, we performed the carrageenan-induced peritonitis model. Intraperitoneal administration of carrageenan produces a sustained increase in postcapillary venule permeability, thereby leading to increased cellular infiltration, particularly of neutrophils (Malech and Gallin, 1987). Thus, this model of acute inflammation allows the quantification of leukocytes that migrate into the peritoneal cavity under the action of chemotactic agents, mainly leukotrienes and cytokines, and is sensitive to the action of non-steroidal antiinflammatory drugs (Brooks and Day, 1991). The results of present study showed that pre-treatment with carvacryl acetate significantly decrease the leukocytes count, as well as neutrophils that migrated into the peritoneal cavity. These data suggest that the carvacryl acetate-mediated anti-inflammatory effect involves, in part, inhibition of neutrophil migration into the injury site.

To confirm these results, we evaluated the levels of myeloperoxidase in inflammatory exudate. Myeloperoxidase (MPO) is an enzyme secreted by neutrophils at inflammatory sites that induce damage to adjacent tissue, contributing to the pathogenesis of inflammation; it is also widely used as a marker of neutrophil infiltration (Vlasova et al., 2012). Our results showed that pretreatment with carvacryl acetate significantly reduced levels of MPO in the peritoneal exudate when compared with the carrageenan group. The results of this evaluation confirm the peritonitis test, indicating that the anti-inflammatory activity of carvacryl acetate involves, among other parameters, decreased neutrophil migration.

In addition to cell migration, carrageenan-induced peritonitis also involves plasma exudation and production of mediators such as nitric oxide, IL-1 $\beta$, TNF- $\alpha$ and IL-6 (Salvemini et al., 1996; Loram et al., 2007). Considering this information, we evaluated the effect of carvacryl acetate on IL-1 $\beta$ and TNF- $\alpha$ levels in the peritoneal exudate. The results found showed that the carvacryl acetate significantly decreased the concentrations of IL-1 $\beta$, when compared with carrageenan group; however, it did not reduced TNF- $\alpha$ level. These data suggest that the antiinflammatory effect of the carvacryl acetate may be due to the inhibition of the production of IL-1 $\beta$ at inflammatory sites. IL- $1 \beta$ is a pleiotropic cytokine that plays a key role in the innate immune response and is associated with the reduction of cell migration and exudation (Vigil et al., 2008). This pro-inflammatory cytokine promotes the expression of adhesion molecules, leukocyte migration, increased vascular permeability and transendothelial migration (Hallegua and Weisman, 2002).

To limit the deleterious consequences of prolonged inflammatory reaction, the release of pro-inflammatory cytokines is followed by the release of anti-inflammatory cytokines, such as IL-4, IL-10, and IL-13. Studies have shown that IL-10 has been found as a potent leukocyte deactivator, which blocked TNF- $\alpha$, IL-1, IL-6, IL-8 (Cyktor and Turner, 2011). Other authors demonstrated that the anti-inflammatory effect of carvacrol is, at least in part, dependent of increase of IL-10 levels (Lima et al., 2013). Thus, we investigated the possibility that IL-10 production also contributes to the anti-inflammatory effect of carvacryl acetate. Our present findings are consistent with the results of Lima et al. (2013). In our study, we also demonstrated that carvacryl acetate enhanced the IL-10 levels in carrageenan-induced peritonitis in mice. Thus, carvacryl acetate, like carvacrol, can be able to modify the number of neutrophills and actively interfere with anti-inflammatory and proinflammatory signalling pathways by inducing production of IL-10 and reducing IL- $1 \beta$ release.

Mediators produced at the sites of inflammation have been known to produce pain through the activation or sensitization of nociceptors adjacent to the injured tissue (Carvalho et al., 2013). Experimental models of inflammatory pain in rodents have been successfully employed to reproduce this kind of pain and are used to search new anti-inflammatory and analgesic drugs (Andrade et al., 2012).

Acetic acid-induced writhing is a visceral pain model which has been largely used for the evaluation of peripheral anti-nociceptive activity because of its high sensitivity (Santos et al., 2011). Acetic acid induces local production of inflammatory mediators, including prostaglandins, serotonin, histamine, bradykinin and substance $P$, which will sensitize the nociceptors leading to hyperalgesia (Chu et al., 2008; Serhan and Haeggstrom, 2010). Pretreatment with the carvacryl acetate significantly decreased the amount of writhing induced by acetic acid in mice. The anti-nociceptive effect demonstrated by carvacryl acetate in this experimental model suggests that it acts through the inhibition of the synthesis or action of inflammatory mediators that contribute to the development of inflammatory pain. Interestingly, this finding confirms our results obtained in experimental models of inflammation, where it was observed that the carvacryl acetate significantly reversed the edema of all inflammatory mediators tested, namely histamine, serotonin and prostaglandin $\mathrm{E}_{2}$. 
The hot plate test is a specific central nociceptive test in which agents exert their analgesic effects via supraspinal and spinal receptors (Mbiantcha et al., 2011). The results obtained showed that carvacryl acetate presented significant anti-nociceptive effect in the hot-plate test. These data suggest the participation of central mechanisms in the anti-nociceptive effects of the carvacryl acetate since both behavioral components that were evaluated in this experimental model, namely paw licking and jumping, are considered to be supraspinally integrated responses (Le Bars et al., 2001).

Another model of nociception that has been extensively used to verify the anti-nociceptive effect noted in new compounds is the formalininduced paw licking test (Sani et al., 2012). This model evaluates two distinct phase of nociception. The first phase, classified as a neurogenic pain, is an acute response observed immediately after the administration of formalin, persisting for $5 \mathrm{~min}$ and that occurs through direct chemical stimulation promoted by formalin on nociceptors, in type $\mathrm{C}$ and part of the $\mathrm{A} \delta$ afferent fibers; it is also associated with the release of excitatory amino acids, as glutamate, aspartate, taurine and glycine that are known to be involved in the transmission of peripheral nociception (Verma et al., 2005; Malmberg and Yaksh, 1995). The second phase appears between 15 and 60 min after the formalin administration, classified as an inflammatory pain, and is a tonic response associated with the release of chemical mediators such as histamine, serotonin, bradykinin, prostaglandins and excitatory amino acids (Sani et al., 2012).

The achieved results in current study evidenced that the carvacryl acetate inhibited both phases of the formalin-induced nociception. These findings strongly confirms its ability to act at central nociceptive level, by inhibiting the neurogenic phase, corroborating with the results found in the hot plate test, besides acting also at the peripheral level, by inhibiting the inflammatory phase, confirming the results found in the acetic acid-induced writhing test.

Notably opioids and non-steroidal anti-inflammatory drugs (NSAIDs) are the classic anesthetics currently used. However, there are several other mechanisms by which the nociception can be reversed; thus, emerging therapies are designed to reduce the nociceptive process by targeting inflammatory mediators (kinins, prostanoids, prostaglandins, cytokines, chemokines) as well as ligand-gated ion channels (Transient Receptor Potential Vanilloid-TRPV, Neuronal Nicotinic Receptors-NNRs, N-methyl-D-aspartate-NMDA, metabotropic glutamate receptor-mGluR) and voltage-regulated sodium and calcium channels (Dray, 2008).

Based on these considerations, we assess the possible mechanisms of anti-nociception of the carvacryl acetate. For this purpose, we evaluated the participation of the opioid pathway in this effect. However, the administration of naloxone, a nonselective opioid antagonist, did not reverse the anti-nociceptive effect of carvacryl acetate, showing that there is no participation of the opioid pathway.

Because of this, there was the necessity to evaluate other possible mechanisms by which the carvacryl acetate exerts its analgesic effect. Thus, were performed tests of nociception capsaicin and glutamate for observing the participation of these pathways.

The capsaicin-induced nociception is brought about by the activation of the capsaicin receptor, also known as the transient receptor potential vanilloid, denominated TRPV, a ligand-gated non-selective cation channel in primary sensory neurons (Capasso and Calignano, 1988). Some analgesia strategies aim at developing either TRPV agonists or antagonist drugs to attenuate excitability in sensory fibers. TRPV agonists, at high doses, promote receptor desensitization or a reversible sensory nerve terminal degeneration because of the prolonged cation influx into the nerve, osmotic damage and metabolic collapse (Szallasi and Blumberg, 1999), while antagonists aim at attenuating peripheral nerve fiber sensitivity by blocking TRPV signal transduction (Gavva et al., 2005; Wang et al., 2007). The data obtained in this work show that the carvacryl acetate produced a neurogenic inhibition against capsaicin-induced nociception indicating its ability to inhibit nociceptive transmission initiated by TRPV activation.
Another attempt in the modulation of carvacryl acetate-mediated antinociception was to evaluate the involvement of the glutamatergic system. Glutamate is a major excitatory neurotransmitter in the central nervous system (Beirith et al., 2002). The glutamatergic receptors, both ionotropic and metabotropic glutamate receptors (iGluR and mGluRs), significantly contribute to nociceptive neurotransmission under the development and maintenance of pain responsiveness (Mao et al., 1992). The nociception induced by glutamate involves peripheral, spinal and supraspinal sites of action (Santos et al., 2005). Thus, activation of glutamate receptors, especially NMDA receptors, is involved in the development of spinal hyperexicitability and persistent pain transmission (Petrenko et al., 2003). Our results provide evidence that carvacryl acetate exerts a pronounced anti-nociception in glutamate-induced pain, indicating that there is the involvement of the glutamatergic pathway.

A relevant observation about the behavioral effects of carvacryl acetate evaluated in this work is the fact that it did not impair motor performance of mice evaluated in the rotarod test, which was used to exclude the possibility that carvacryl acetate caused motor relaxation and sedation (Sulaiman et al., 2010). Thus, the results of the nociception tests of carvacryl acetate would be not influenced by induced motor impairment.

\section{Conclusion}

In summary, our results show that the carvacryl acetate presents anti-inflammatory and anti-nociceptive effects. The present data provide evidence that in the carvacryl acetate-mediated antiinflammatory effect, the mechanisms involved are inhibition of inflammatory the mediators histamine, serotonin and prostaglandins, as well as a decrease of mast cell degranulation, pro-inflammatory cytokines and neutrophil migration. Our results also show that the carvacryl acetate-mediated anti-nociceptive effect occurs centrally and peripherally, through the involvement of capsaicin and glutamate pathways and decreased inflammatory mediators.

\section{Conflict of interest statement}

The authors report no conflict of interest.

\section{Acknowledgments}

The authors gratefully acknowledge to the National Counsel of Technological and Scientific Development, CNPq (Brazil) and to the Research Foundation for the State of Piauí-Brazil (FAPEPI) for financially supporting this work.

\section{References}

Andrade EL, Meotti FC, Calixto JB. TRPA1 antagonists as potential analgesic drugs. Pharmacol Ther 2012;133:189-204.

Bano S, Javed K, Ahmad S, Rathish IG, Singh S, Chaitanya M, et al. Synthesis of some novel chalcones, flavanones and flavones and evaluation of their anti-inflammatory activity. Eur J Med Chem 2013;65:51-9.

Beena N, Kumar D, Rawat DS. Synthesis and antioxidant activity of thymol and carvacrol based Schiff bases. Bioorg Med Chem Lett 2013;23:641-5.

Beirith A, Santos ARS, Calixto JB. Mechanisms underlying the nociception and paw edema caused by injection of glutamate into the mouse paw. Brain Res 2002;924:219-28.

Bradley PP, Priebat DA, Christensen RD, Rothstein G. Measurement of cutaneous inflammation: estimation of neutrophil content with an enzyme marker. J Invest Dermatol 1982;78:206-9.

Brooks PM, Day RO. Non-steroidal anti-inflammatory drugs differences and similarities. N Engl J Med 1991;324:1716-25.

Calixto JB. Twenty-five years of research on medicinal plants in Latin America: a personal review. J Ethnopharmacol 2005;100:131-4.

Capasso A, Calignano A. Synergism between the sedative action of kava extract and D, L-kavain. Acta Theriol 1988:14:249-56.

Carvalho V, Fernandes L, Conde T, Zamith H, Silva R, Surrage A, et al. Antinociceptive activity of Stephanolepis hispidus skin aqueous extract depends partly on opioid system activation. Mar Drugs 2013;11:1221-34.

Chaves LS, Nicolau LAD, Silva RO, Barros FCN, Freitas ALP, Aragão KS, et al. Antiinflammatory and antinociceptive effects in mice of a sulfated polysaccharide fraction extracted from the marine red algae Gracilaria caudata. Immunopharmacol Immunotoxicol 2013;35:93-100. 
Chu C, Huang Y, Chen YF, Wu JH, Rahman K, Zheng HC, et al. Antinociceptive activity of aqueous fraction from the $\mathrm{MeOH}$ extracts of Paederia scandensin mice. J Ethnopharmacol 2008;118:177-80.

Claudino RF, Kassuya CAL, Ferreira J, Calixto JB. Pharmacological and molecular characterization of the mechanisms involved in prostaglandin E2-induced mouse paw edema. J Pharmacol Exp Ther 2006;318:611-8.

Coussens LM, Werb Z. Inflammation and cancer. Nature 2002;420:860-7.

Cyktor JC, Turner J. Interleukin-10 and immunity against prokaryotic and eukaryotic intracellular pathogens. Infect Immun 2011;79:2964-73.

Datti F, Datti M, Antunes E, Teixeira NA. Influence of chronic unpredictable stress on the allergic responses in rats. Physiol Behav 2002;77:79-83.

Déciga-Campos M, Palacios-Espinosa JF, Reyes-Ramírez A, Mata R. Antinociceptive and anti-inflammatory effects of compounds isolated from Scaphyglottis livida and Maxillaria densa. J Ethnopharmacol 2007;114:161-8.

Dray A. New horizons in pharmacologic treatment for rheumatic disease pain. Rheum Dis Clin North Am 2008;34:481-505.

Dunham NW, Miya TS. A note on a simple apparatus for detecting neurological deficit in rats and mice. J Am Pharm Assoc 1957;46:208-10.

Eddy NB, Leimbach D. Synthetic analgesics. II. Dithienylbutenyl- and dithienylbutylamines. J Pharmacol Exp Ther 1953;107:385-93.

Fasmer OB, Berge OG, Hole K. Changes in nociception after lesions of descending serotonergic pathways induced with 5,6-dihydroxytryptamine. Different effects in the formalin and tail-flick tests. Neuropharmacology 1986;24:729-34.

Gavva NR, Tamir R, Qu Y, Klionsky L, Zhang TJ, Immke D, et al. AMG 9810 [(E)-3-(4-t-butylphenyl)-N-(2,3-dihydro-benzo[b][1,4] dioxin-6-yl)acrylamide], a novel vanilloid receptor 1 (TRPV1) antagonist with antihyperalgesic properties. J Pharmacol Exp Ther 2005;313:473-84.

González CP, Vega RS, González-Chávez M, Sánchez MAZ, Gutiérrez SP. Antiinflammatory activity and composition of Senecio salignus Kunth. BioMed Res Int 2013:2013:1-4.

Hallegua DS, Weisman MH. Potential therapeutic uses of interleukin 1 receptor antagonists in human diseases. Ann Rheum Dis 2002;61:960-7.

Hunskaar S, Fasmer OB, Hole K. Formalin test in mice, a useful technique for evaluating mild analgesics. J Neurosci Methods 1985;14:69-76.

Ipek E, Zeytinoglu H, Okay S, Tuylu BA, Kurkcuoglu M, Baser KHC. Genotoxicity and antigenotoxicity of Origanum oil and carvacrol evaluated by Ames Salmonella/ microsomal test. Food Chem 2005;93:551-6.

Kaur G, Hamid H, Ali A, Alam MS, Athar M. Antiinflammatory evaluation of alcoholic extract of galls of Quercus infectoria. J Ethnopharmacol 2004;90:285-92.

Klein G, Rüben C, Upmann M. Antimicrobial activity of essential oil components against potential food spoilage microorganisms. Curr Microbiol 2013;67:200-8.

Koster R, Anderson M, Debeer EI. Acetic acid for analgesic screening. Fed Proc 1959;18: 412-8.

Landa P, Kokoska L, Pribylova M, Vanek T, Marsik P. In vitro anti-inflammatory activity of carvacrol: inhibitory effect on cox-2 catalyzed prostaglandin $\mathrm{E}_{2}$ biosynthesis. Arch Pharm Res 2009;32:75-8.

Le Bars D, Gozariu M, Cadden SW. Animal models of nociception. Pharmacol Rev 2001;53: 597-652.

Lima MS, Quintans-Júnior LJ, Santana WA, Kaneto CM, Soares MBP, Villarreal CF. Anti-inflammatory effects of carvacrol: evidence for a key role of interleukin-10. Eur J Pharmacol 2013;699:112-7.

Linardi A, Costa SKP, De Silva GR, Antunes E. Involvement of kinins, mast cells and sensory neurons in the plasma exudation and paw edema induced by staphylococcal enterotoxin B in the mouse. Eur J Pharmacol 2000;399:235-42.

Loram LC, Fuller A, Fick LG, Cartmell T, Poole S, Mitchell D. Cytokine profiles during carrageenan-induced inflammatory hyperalgesia in rat muscle and hind paw. J Pain 2007;8:127-36.

Malech HL, Gallin JI. Current concepts: immunology-neutrophils in human diseases. N Engl J Med 1987; 317:687-94.

Malmberg AB, Yaksh TL. Cyclooxygenase inhibition and the spinal release of prostaglandin E2 and amino acid evoked by paw formalin injection: a microdialysis study in unanesthetized rats. J Neurosci 1995;14:2768-76.

Mao J, Price DD, Hayes RL, Lu J, Mayer DJ. Differential roles of NMDA and non-NMDA receptor activation in induction and maintenance of thermal hyperalgesia in rats with painful peripheral mononeuropathy. Brain Res 1992;598:271-8.

Mbiantcha M, Kamanyi A, Teponno RB, Tapondjou AL, Watcho P, Nguelefack TB. Analgesic and anti-inflammatory properties of extracts from the bulbils of Dioscorea bulbifera L. var sativa (Dioscoreaceae) in mice and rats. Evid Based Complement Alternat Med 2011;10:1-9.
Medzhitov R. Origin and physiological roles of inflammation. Nature 2008;454:428-35.

Melo FHC, Rios ERV, Rocha NFM, Citó MCO, Fernandes ML, Sousa DP, et al. Antinociceptive activity of carvacrol (5-isopropyl-2-methylphenol) in mice. J Pharm Pharmaco 2012;64:1722-9.

Moraes J, Carvalho AA, Nakano E, de Almeida AA, Marques TH, Andrade LN, et al. Anthelmintic activity of carvacryl acetate against Schistosoma mansoni. Parasitol Res 2013;112:603-10.

Morris CJ, Ferreira SH, Vane JR. Carrageenan-induced paw edema in the rat and mouse. Methods Mol Biol 2003;225:115-21.

Niazi J, Singh P, Bansal Y, Goel RK. Anti-inflammatory, analgesic and antipyretic activity of aqueous extract of fresh leaves of Cocciniaindica. Inflammopharmacol 2009;17: 239-44.

Perez-Gurrero C, Herrera MD, Ortiz R, Alvarez de Sotomayor M, Fernandez MA. A pharmacological study of Cecropia obtusifolia Betrol aqueous extract. J Ethnopharmacol 2001;76:279-84.

Petrenko AB, Yamakura T, Baba H, Shimoji K. The role of N-methyl-D-aspartate (NMDA) receptors in pain: a review. Anesth Analg 2003;97:1108-16.

Rady JJ, Campbell WB, Fujimoto JM. Antianalgesic action of nociception originating in the brain is mediated by spinal prostaglandin $E_{2}$ in mice. J Pharmacol Exp Ther 2001;296: 7-14.

Rodriguez-Vita J, Lawrence T. The resolution of inflammation and cancer. Cytokine Growth Factor Rev 2010;21:61-5.

Sakurada T, Matsumura T, Moriyama T, Sakurada C, Ueno S, Sakurada S. Differential effects of intraplantar capsazepine and ruthenium red on capsaicin-induced desensitization in mice. Pharmacol Biochem Behav 2003;75:115-21.

Salvemini D, Wang ZQ, Wyatt PS, Bourdon DM, Marino MH, Manning PT, et al. Nitric oxide: a key mediator in the early and late phase of carrageenan-induced rat paw inflammation. Br J Pharmacol 1996;118:829-38.

Sani MH, Zakaria ZA, Balan T, The LK, Salleh MZ. Antinociceptive activity of methanol extract of Muntingia calabura leaves and the mechanisms of action involved. Evid Based Complement Alternat Med 2012;2012:1-10.

Santos AR, Gadotti VM, Oliveira GL, Tibola D, Paszcuk AF, Neto A, et al. Mechanisms involved in the antinociception caused by agmatine in mice. Neuropharmacology 2005;48:1021-34

Santos EN, Lima JCS, Noldin VF, Cechinel-Filho V, Rao VSN, Lima EF, et al Antiinflammatory, antinociceptive, and antipyretic effects of methanol extract of Cariniana rubra stem bark in animal models. An Acad Bras Cienc 2011;2:557-66.

Serhan CN, Haeggstrom JZ. Lipid mediators in acute inflammation and resolution: eicosanoids, PAF, resolvins and proteins. Cambridge: Cambridge University Press; 2010153-74.

Silva VG, Silva RO, Damasceno SRB, Carvalho NS, Prudêncio RS, Aragão KS, et al Anti-inflammatory and antinociceptive activity of epiisopiloturine, an imidazole alkaloid isolated from Pilocarpus microphyllus. J Nat Prod 2013;76:1071-7.

Sulaiman MR, Padzil A, Shaari K, Khalid S, Shaikmossadeq W, Shahmohamad A, et al Antinociceptive activity of Melicopep telefolia ethanolic extract in experimental animals. J Biomed Biotechnol 2010;2010:1-6.

Szallasi A, Blumberg PM. Vanilloid (Capsaicin) receptors and mechanisms. Pharmacol Rev 1999;51:159-212.

Verma PR, Joharapurkar AA, Chatpalliwar VA, Asnani AJ. Antinociceptive activity of alcoholic extract of Hemidesmus indicus R. Br. in mice. J Ethnopharmacol 2005;102: 298-301.

Vigil SVG, Liz R, Medeiros YS, Frode TS. Efficacy of tacrolimus in inhibiting inflammation caused by carrageenan in a murine model of air pouch. Transpl Immunol 2008;19:25-9.

Vincenzi MD, Stammati A, Vincenzi AD, Silano M. Constituents of aromatic plants: carvacrol. Fitoterapia 2004;75:801-4.

Vlasova II, Sokolov AV, Arnhold J. The free amino acid tyrosine enhances the chlorinating activity of human myeloperoxidase. J Inorg Biochem 2012;106:76-83.

Vogel AI, Tatchell AR, Furnis BS, Hannaford AJ, Smith PWG. Vogel's text book of practical organic chemistry. 5th ed. Englewood Cliffs: Prentice-Hall; 1996

Wang HL, Katon J, Balan C, Bannon AW, Bernard C, Doherty EM, et al. Vanilloid receptor-1 antagonists: 3. The identification of a second-generation clinical candidate with improved physicochemical and pharmacokinetic properties. J Med Chem 2007;50: 3528-39.

Winter CA, Risley EA, Nuss GW. Carrageenin-induced edema in hind paw of the rat as an assay for antiiflammatory drugs. Proc Soc Exp Biol Med 1962;111:544-7.

Yanishlieva N, Marinova EM, Gordon MH, Raneva VG. Antioxidant activity and mechanism of action of thymol and carvacrol in two lipid systems. Food Chem 1999;64: 59-66. 